\begin{tabular}{|l|l|l}
\hline RESEARCH ARTICLE & Open access & http://www.foliahort.ogr.ur.krakow.pl \\
\hline
\end{tabular}

\title{
Characterisation and evaluation of interspecific cross-incompatibility in two Delphinium species
}

\author{
Ying Cheng ${ }^{1,2}$, Wenling Guan ${ }^{3, *}$, Fan Li ${ }^{2, *}$ \\ ${ }^{1}$ School of Agriculture, Yunnan University, Kunming 650504, China \\ ${ }^{2}$ Floriculture Research Institute, Yunnan Academy of Agricultural Sciences, National Engineering Research Center for \\ Ornamental Horticulture, Key Laboratory for Flower Breeding of Yunnan Province, Kunming 650200, China \\ ${ }^{3}$ College of Horticulture and Landscape, Yunnan Agricultural University, Kunming 650201, China
}

\begin{abstract}
Delphinium yunnanense is an endemic species in the Yunnan Province of China, while Delphinium elatum 'Guardian Blue' is widespread as cut flowers in the world. They all bloom attractive blue flowers, which are a crucial ornamental trait for floriculture. In this experiment, the cross-compatibility between D. yunnanense and D. elatum was characterised and evaluated. The results showed that a strong cross-incompatibility was observed in D. yunnanense $\times$ D. elatum, resulting in hybrid sterility. The $\mathrm{F}_{1}$ hybrid generation produced neither fruits nor seeds. The cross-incompatibility of the hybrids resulted from the disturbed structure of the pollen tubes penetrating pistil style and callose deposits on stigma and in style. Moreover, the germination rate of $D$. elatum $\times$ D. yunnanense $\mathrm{F}_{1}$ seed was lower than their own allogamic crosses, although there was no difference in fruit set rate. The results confirmed the cross-incompatibility between D. yunnanense and D. elatum, suggesting that $D$. elatum is more suitable as a maternal parent for hybridisation breeding. Our study characterised and evaluated the interspecific cross-compatibility through the pollen-stigma interaction and the reproductive system in Delphinium, which could provide the basis for the development and utilisation of potential ornamental traits in Delphinium.
\end{abstract}

Keywords: allogamic cross, compatibility, Delphinium, pollen-stigma interaction, reciprocal cross, reproduction

\section{INTRODUCTION}

The genus Delphinium, a member of the Ranunculaceae family, is widely distributed in the temperate regions of the Northern Hemisphere (Malyutin, 2001). Delphinium comprises about 350 species of perennial flowering plants, of which 173 species have been described in China (Wang and Warnock, 2001). In particular, most of the species are concentrated in Southwest China, which is one of the most important distribution centres and covers most of the morphological primitive representatives (Yuan and Yang, 2008). Yunnan Province, known as the 'Kingdom of Plant', is a centre of species diversity and endemism of Delphinium, consisting of 49 species and 13 varieties (Yuan and Yang, 2019). According to reports, there are 24 species with a high ornamental value that has potential for development and utilisation, such as D. yunnanense and D. grandiflorum (Guan and Li, 2002). Moreover, Delphinium is widely cultivated in the world for a long time, that is, Delphinium elatius flore plena was cultured by J. Parkinson in Western Europe as early as 1640 (Legro, 1961). In floriculture, the most important hybrid species is D. elatum, which developed as a series of 4,000 named cultivars from hundreds of different breeders and growers in the past few decades (Royal Horticultural Society, 1949). Besides, through hybridisation, mutagenesis, chemical and radiation treatment of different species within the 
genus Delphinium, a wide range of flower colours from white, yellow, red, violet to blue were introduced into the new cultivars as well as improved quality of cut flower, mildew resistance and toughness of the stems (Mehlquist et al., 1943; Wegulo and Vilchez, 2008; Chen et al., 2011; Lin et al., 2014). In addition to the ornamental purposes of showy flowers, the plants of Delphinium contain various alkaloids with spectacular medicinal values, such as diterpenoid alkaloids, trichodelphinines and flavonoids, which increase the utilisation and economic value of Delphinium (Chen et al., 2011; Agnihotri et al., 2014; Lin et al., 2014).

Delphinium yunnanense (D. yunnanense) is an endemic species in the Yunnan Province of China with blue flowers, which is considered a precious ornamental germplasm to be developed. However, Delphinium elatum (D. elatum) 'Guardian Blue' is one of the most popular flowers in the world as an attractive high-grade cut flower. Both species are the potential candidates for developing new Delphinium varieties with blue flowers through hybridisation. The chromosome number and the ploidy level of many species and varieties in the genus Delphinium have been investigated (Legro, 1961; Yuan and Yang, 2008). Most of the wild species, including D. yunnanense, are diploids with 16 chromosomes $(2 n=2 x=16)$, whereas $D$. elatum was tetraploid $(2 n=4 x=32)$. An intraspecific difference in chromosome number was detected neither in diploid nor in tetraploid species (Legro, 1961; Yuan and Yang, 2008). Nevertheless, the breeders have had success in interploidy crosses using different Delphinium species. For example, the frequently used tetraploid cultivars of D. elatum were widely crossed with diploid species to form sterile triploid hybrids, which, after the colchicine treatment, became fertile, produced seeds and viable seedlings (Lewis et al., 1951; Samuelson, 1957; Tjebbes, 2010). Moreover, the reproductive system with pollenstigma interactions has been previously investigated in D. grandiflorum, D. cardinale, D. nudicaule, D. barbeyi and $D$. nuttallianum and their interspecific hybrids (Honda et al., 1999; Williams, 2007; Elliott and Irwin, 2009; Briggs et al., 2016). Some studies have shown that the breeding system of Delphinium is facultative xenogamy or obligate outcrossing, accompanying with partly self-compatibility requiring pollinators (Price and Waser, 1979; Williams et al., 2001; Zhang et al., 2014). Self-incompatibility (0-50\%) and autogamy (1$90 \%$ ) in different degrees among different species in Delphinium have been reported (Macior, 1975; Varney, 1979; Powell and Jones, 1983; Bosch et al., 2001). To our knowledge, both of the studied species are capable of selfing; however, no previous study concerned the cross-compatibility in the species of D. yunnanense and D. elatum.

In this study, we explored and investigated the interspecific cross-compatibility of D. yunnanense and D. elatum 'Guardian Blue' to establish the mating ability of these two Delphinium species, which could be helpful in developing new varieties of these ornamental plants.

\section{MATERIALS AND METHODS}

\section{Plant material and growth conditions}

D. yunnanense and a commercial cultivar of D. elatum 'Guardian Blue' were used in this study. The seeds of D. yunnanense used in this study were randomly collected in natural habitats (N25 $\left.5^{\circ} 7^{\prime} 33^{\prime \prime}, \mathrm{E} 102^{\circ} 45^{\prime} 31^{\prime \prime}\right)$ in Kunming, Yunnan Province at an altitude of 2,139 m. The seeds of D. elatum 'Guardian Blue' were obtained from the local flower market with 500 seeds in the same bag. A total of 100 seeds of each species were first germinated in the petri dish covering with a moist filter paper. Then, 50 seedlings of each species were separately transferred and planted in 100-well plant trays. After the root system filled the holes, the plants were separately planted in pots $($ diameter $=8 \mathrm{~cm}$, height $=8 \mathrm{~cm})$ filled with substrate (red soil:peat $=1: 1$ ) and grown in the solar greenhouse (without heating) at the experimental farm of Yunnan Agricultural University. The flowering dynamics were continuously observed when the plants begin to bloom.

\section{Pollen viability and stigma receptivity}

The examination of pollen viability was conducted with three plants of each species during anthesis based on in vivo germination method (He et al., 2017). In a full flowering stage, fresh pollen was collected every $2 \mathrm{~h}$ from three flowers per plant and was incubated for $4 \mathrm{~h}$ at $25^{\circ} \mathrm{C}$ in the liquid medium $\left(5 \%\right.$ sucrose, $150 \mathrm{mg} \cdot \mathrm{L}^{-1}$ boric acid and $20 \mathrm{mg} \cdot \mathrm{L}^{-1} \mathrm{CaCl}_{2}$ ) from 9:30 to 15:30. The total number of pollen grains and the number of germinating pollen grains were counted in three separate fields of view per slide under the light microscope. The percentage of germinating pollen was estimated by germinating pollen number/total pollen number $\times 100$. The active pollen was identified by the length of the pollen tube longer than the diameter of pollen grain, otherwise recorded as inactive pollen (Rodriguez-Riano and Dafni, 2000).

Stigma receptivity was examined by the benzidinehydrogen peroxide method (Li et al., 2018). During anthesis (from day 1 to day 8), three flowers at the fullopen stage of each species were collected every day and were soaked in the benzidine-hydrogen peroxide solution ( $1 \%$ benzidine: $3 \%$ hydrogen peroxide: water $=$ 4:11:22, v/v, Cato Research Chemicals, Inc.). The receptive stigma shows peroxidase activity and turns blue with a mass of bubbles surrounding it. The depth of the blue color and number of bubbles indicate the intensity of stigma receptivity.

\section{Observation of pollen-stigma interaction}

To observe the pollen-stigma interaction in interspecific hybridisation, the reciprocal crosses between $D$. yunnanense and D. elatum were conducted as well as intraspecific allogamic crosses. The D. elatum $\times$ D. yunnanense was treated as an orthogonal cross, and the $D$. yunnanense $\times D$. elatum referred to reciprocal cross. To avoid self-pollination, the flowers were 
emasculated and isolated by plastic bags until the anther dehiscence. This treatment was applied in each cross combination with a random selection of 10 plants (three flowers per plant). Before pollination, the stigma was examined by a magnifier for a secretion check. The pollen sac was then gently dipped onto the stigma with secretions using tweezers. Each stigma was pollinated several times to ensure a sufficient amount of pollen and was covered by bags after pollination.

The pistils of each cross were collected at 2, 4, 6, 24, 72 and $120 \mathrm{~h}$ after pollination and fixed in Carnoy's solution (ethanol: glacial acetic acid $=3: 1, \mathrm{v} / \mathrm{v}$, Shanghai Fusheng Industrial Co., Ltd.) for $24 \mathrm{~h}$ at $4^{\circ} \mathrm{C}$ and then stored in $70 \%$ of ethanol. The samples were then treated with $6 \mathrm{~mol} \cdot \mathrm{L}^{-1} \mathrm{NaOH}$ for $12 \mathrm{~h}$. After repeated rinsing with distilled water, the pistils were immersed in a $0.1 \%$ water-soluble aniline blue solution (dissolved in $0.1 \mathrm{~mol}$. $\mathrm{L}^{-1} \mathrm{~K}_{3} \mathrm{PO}_{4}$, ScyTek Laboratories) for $24 \mathrm{~h}$. The stained ovaries were then observed with Leika fluorescent microscope under ultraviolet light to investigate pollen adherence, pollen germination, callose formation and pollen tube growth. For each treatment, six pistils in three replications were used to calculate the average number of pollen grains.

\section{Calculation of fruit setting and germination rate}

Thirty flowers were used to evaluate the fruit setting for each cross. The number of mature fruits and seeds per fruit were counted, and the thousand kernel weight (TKW) was measured. The fruit-setting rate was calculated by the formula: the number of mature fruits/ the number of pollinated flowers $\times 100$.

The $F_{1}$ seeds of each cross were germinated in a presterilised culture dish (Guangzhou Jet Bio-Filtration Co., Ltd., TCD000060) on wet filter papers. The seeds were then cultivated in environmentally controlled growth chambers (LRH-400-GSI, 400 L; Zhujiang, China) under the condition of $12 \mathrm{~h}$ photoperiod at $25^{\circ} \mathrm{C}$. The experiment was repeated in triplicate (100 seeds per repeat). The germination rate was calculated as germinated seeds/total seeds $\times 100$, in which germinated seeds refer to the sprout length equal to or longer than the seed length.

\section{Statistical analysis}

Data analysis and statistics were performed using Microsoft Excel 2016 and Data Processing System (Tang and Zhang, 2013). One-way and two-way ANOVA with Tukey's HSD post-hoc test was used to compare multiple samples at the 5\% significance level.

\section{RESULTS}

\section{Stages of flower development}

The inflorescence of D. yunnanense and D. elatum is racemose, in which the development of individual flowers is from bottom to top. Eight flowering stages could be identified in the two species throughout the entire flower developmental period, including flower bud stage, stem elongation stage, bud expansion stage, sepal open stage, petal open stage, flower semi-open stage, flower full-open stage, and anther cracked stage (Figure 1). The flower of D. yunnanense contains five large and bright bluish violet sepals, and the real petals are very small and hidden between the staminode and the upper sepal. Besides, there are two blue staminodes with yellow barbs on the ventral surface. For D. elatum, there are two layers of hyacinthine ovate sepals, and petals and staminodes are white. The flowering period of D. yunnanense was about 10 days, whereas the flowers of $D$. elatum can maintain a longer period of 15 days. This may be affected by the number of petals since D. elatum has double petal flowers.

\section{Pollen viability and stigma receptivity}

The pollen viability, estimated in pollen germination in vitro test, of $D$. elatum was significantly weaker than that of D. yunnanense during the day, and the diurnal variation displayed a trend of increase in the morning but decrease in the afternoon (Figure 2). Moreover, the pollen viability of $D$. yunnanense and D. elatum showed a peak at noon (11:30 $\mathrm{AM})$ with germination ratio at $40.89 \% \pm 15.65 \%$ and $18.78 \% \pm 5.18 \%$, respectively. This suggested that Delphinium is better to pollinated around noon, at least in these two tested species.

The observation of stigma receptivity revealed that the stigma of $D$. yunnanense was not receivable at the beginning of the flowering period, but displayed a positive reaction with pollen from $6^{\text {th }}$ day to $8^{\text {th }}$ day (Table 1). This positive reaction was strengthened at the $7^{\text {th }}$ day of flowering and then declined until the end of the measurement. In contrast, the stigma receptivity of D. elatum presented one day earlier than that of D. yunnanense and had a strong receptivity the next day. However, the stigma receptivity of $D$. elatum had a shorter duration than that of D. yunnanense, since it became only partial receivable at the $7^{\text {th }}$ day of flowering.

\section{Pollen-stigma interaction}

The number of pollen grains adhering to the surface of stigma and the germination rate was measured to reflect and evaluate the cross-compatibility of each cross combination.

The results showed that pollination time $(F=73.3260$, $p=0.0000)$ and cross combination $(\mathrm{F}=110.5710$, $p=0.0000$ ) had significant effects on the number of attached pollen grains in Delphinium, and their interaction was significant as well $(F=18.9170$, $p=0.0000$ ) (Table 2). The number of attached pollen grains significantly increased at $24 \mathrm{~h}$ after pollination in four crosses. The number of attached pollen grains of D. yunnanense was significantly higher than that of D. elatum after pollination on any type of stigma (Figure 3). This indicated that the pollen survival rate of D. yunnanense was higher than that of D. elatum, which was in line with the result of pollen viability. However, there was no statistically significant difference in the 


\section{A}
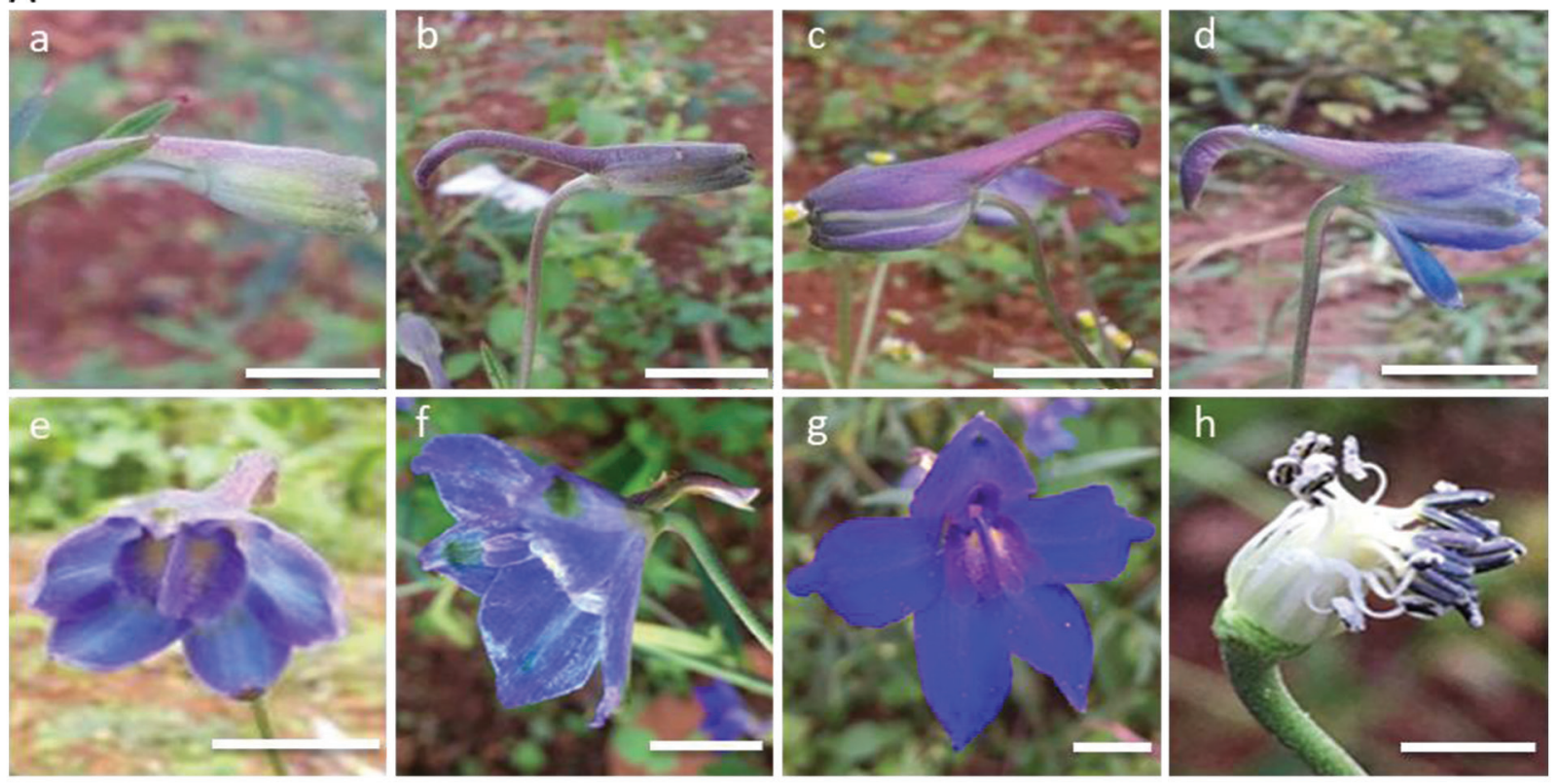

\section{B}
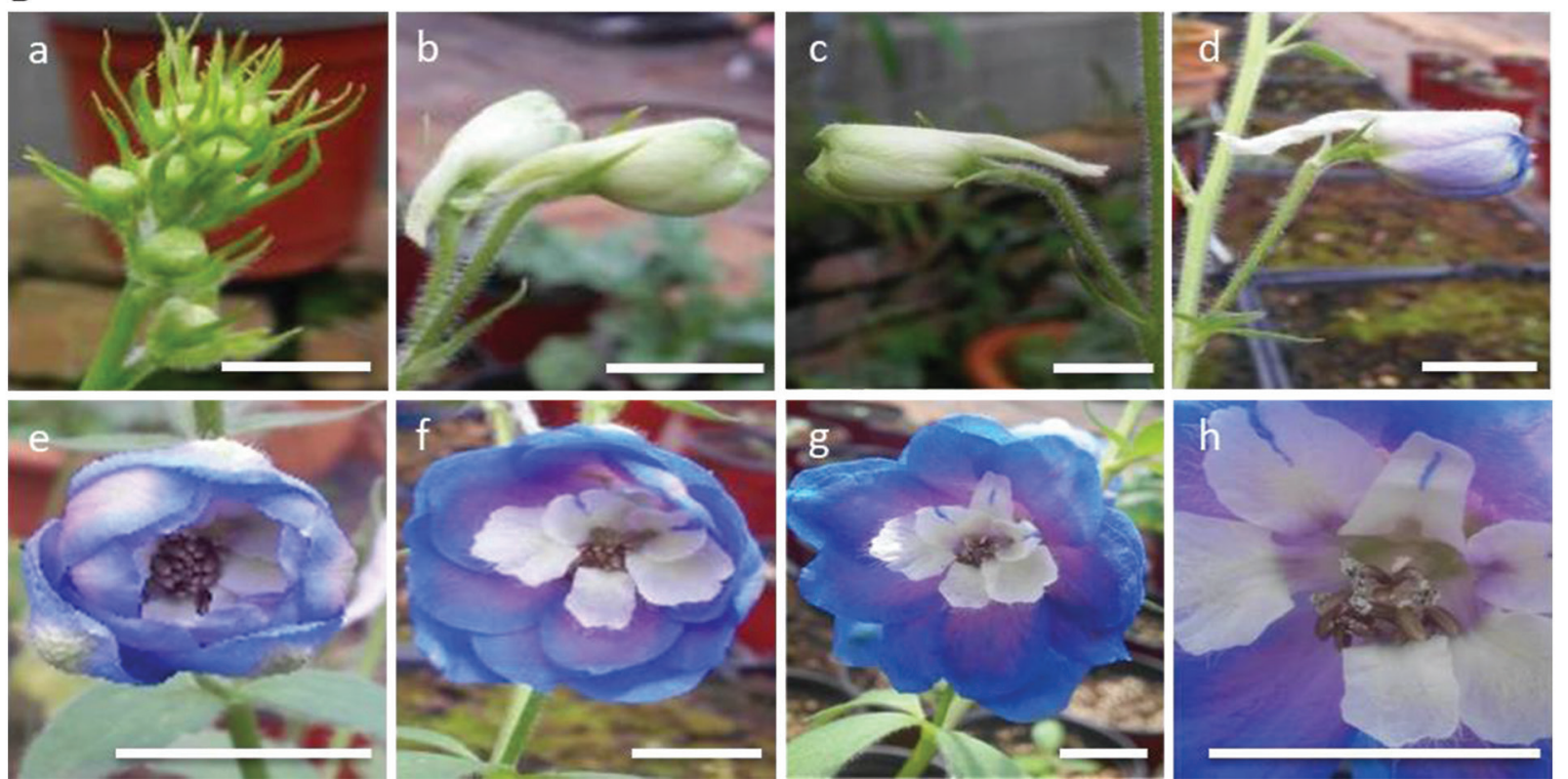

Figure 1. Stages of flower development of D. yunnanense (A) and D. elatum 'Guardian Blue' (B). Bud stage (a), stem elongation stage (b), bud expansion stage (c), sepal open stage (d), petal open stage (e), flower semi-open stage (f), flower full-open stage $(\mathrm{g})$ and anther cracked stage $(\mathrm{h})$. Bar $=1 \mathrm{~cm}$.

number of pollen grains attached to the stigma between interspecies crosses of $D$. elatum $\times$ D. yunannense and intraspecific crosses of D. yunanense, similarly as in the cross of $D$. yunannense $\times D$. elatum and intraspecific crosses of D. elatum.

From the overview of the dynamics of attached pollen grains in four crosses, some pollen grains had been attached to the stigma after $2 \mathrm{~h}$ of pollination (Figure 3). The number of attached pollens in the orthogonal cross $(D$. elatum $\times D$. yunnanense $)$ was higher than that of other three crosses, which were at the same low level in the early period after pollination. This trend continued until $6 \mathrm{~h}$ after pollination, in which the attached pollen grains of $D$. yunnanense allogamic cross (D. yunnanense $\times$ D. yunnanense) dramatically increased over ten-fold (from $10.67 \pm 1.53$ to $118.67 \pm 11.02, n=3$ ). The same result as multiple comparisons, the attached pollens reached the peak after $24 \mathrm{~h}$ of pollination with a significant difference in each cross combination. Then, the attached pollens gradually decreased, except for that of D. yunnanense allogamic cross showing a sharp decrease.

The frequency of germinated pollen grains in different crosses after pollination displayed the same 


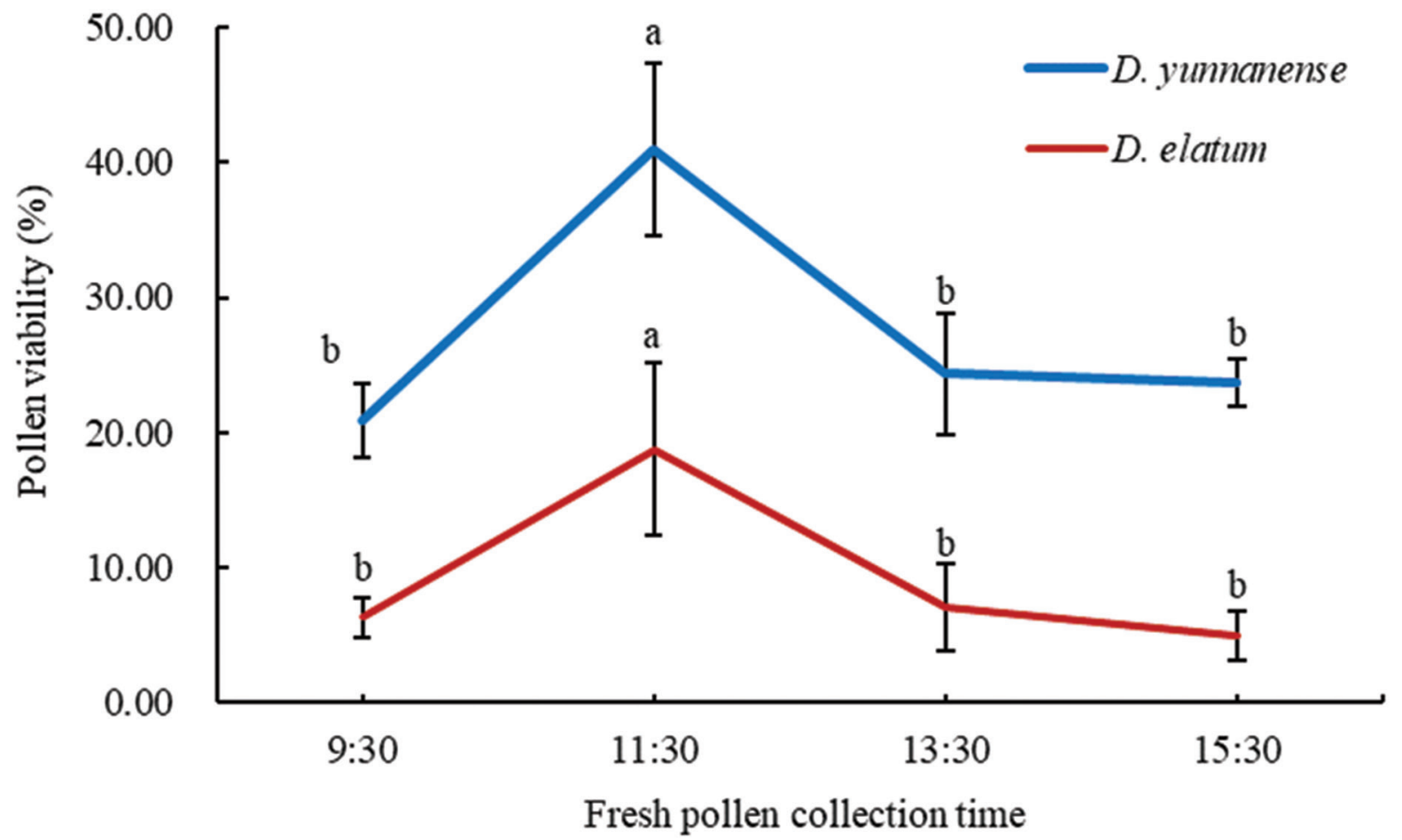

Figure 2. The diurnal variation of pollen viability in D. yunnanense and D. elatum. One-way ANOVA was used to assess statistical significance, and $p$ values were calculated with Tukey's HSD test $(\alpha=0.05)$. Multiple comparisons indicated by small letters were performed in different collection time within the same species. The data represent the mean value \pm standard deviation from three replicates.

Table 1. Stigma receptivity of the full-open stage during the flower opening process in D. yunnanense and D. elatum. '-', stigma not receivable; ' \pm ', partial positive reaction; '+', positive reaction; '++' strong positive reaction.

\begin{tabular}{lcccccccc}
\hline Species & $1^{\text {st }}$ day & $2^{\text {nd }}$ day & $3^{\text {rd }}$ day & $4^{\text {th }}$ day & $5^{\text {th }}$ day & $6^{\text {th }}$ day & $7^{\text {th }}$ day & $8^{\text {th }}$ day \\
\hline $\begin{array}{l}\text { D. yunnanense } \\
\text { D. elatum }\end{array}$ & - & - & - & - & - & + & ++ & + \\
\hline
\end{tabular}

The data were obtained from 10 flowers.

Table 2. Results of statistical analysis about pollination time and cross combination on the number of attached pollen grains in Delphinium.

\begin{tabular}{lccccc}
\hline Source of variation & Sum of square & Degree of freedom & Mean square & $F$ value & $p$ value \\
\hline Pollination time & $27,746.7778$ & 5 & 5549.3556 & 73.3260 & 0.0000 \\
Cross combination & $25,104.2778$ & 3 & 8368.0926 & 110.5710 & 0.0000 \\
Time $\times$ Combination & $21,474.2222$ & 15 & 1431.6148 & 18.9170 & 0.0000 \\
error & 3632.6667 & 48 & 75.6806 & & \\
Total variations & $77,957.9444$ & 71 & & & \\
\hline
\end{tabular}

trend as the attached pollen grains in the corresponding cross combination (Figure 4). There was also a significant interaction of pollination time and cross combination on the germinated pollen number revealed by the multiple comparisons $(F=6.0460, p=0.0000$, Table 3). Moreover, the number of germinated pollen grains reached its peak $24 \mathrm{~h}$ after pollination. The frequency of germinated pollen of D. yunnanense was significantly higher than that of $D$. elatum in four crosses. This was in line with the variation of attached pollens, indicating that the amount of germinated pollen grains was positively correlated with the amount of attached pollens in the species of Delphinium.

\section{Dynamics of pollen tube growth in different cross combinations}

In the orthogonal cross $(D$. elatum $\times D$. yunnanense $)$, most of the pollen grains germinated on stigma $2 \mathrm{~h}$ 


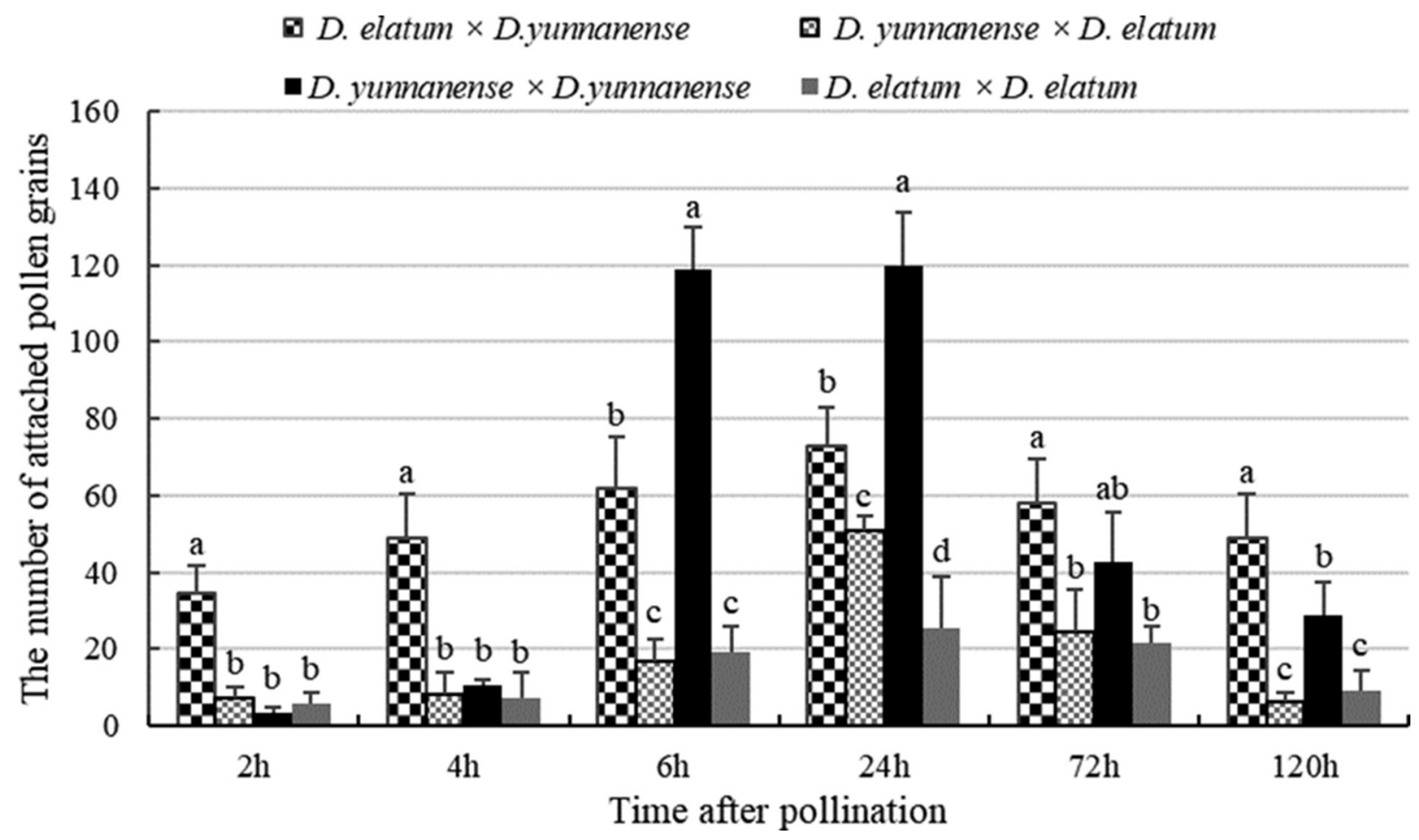

Figure 3. The number of attached pollen grains of each cross combination after different pollination time. One-way ANOVA was used to assess statistical significance, and $p$ values were calculated with Tukey's HSD test $(\alpha=0.05)$. Multiple comparisons indicated by small letters were compared in different cross combinations within the same time after pollination. The data represent the mean value \pm standard deviation from three replicates.
- D. elatum $\times$ D.yunnanense
D. yunnanense $\times D$. elatum
$\square$ D. yunnanense $\times$ D.yunnanense
$\square D$. elatum $\times D$. elatum

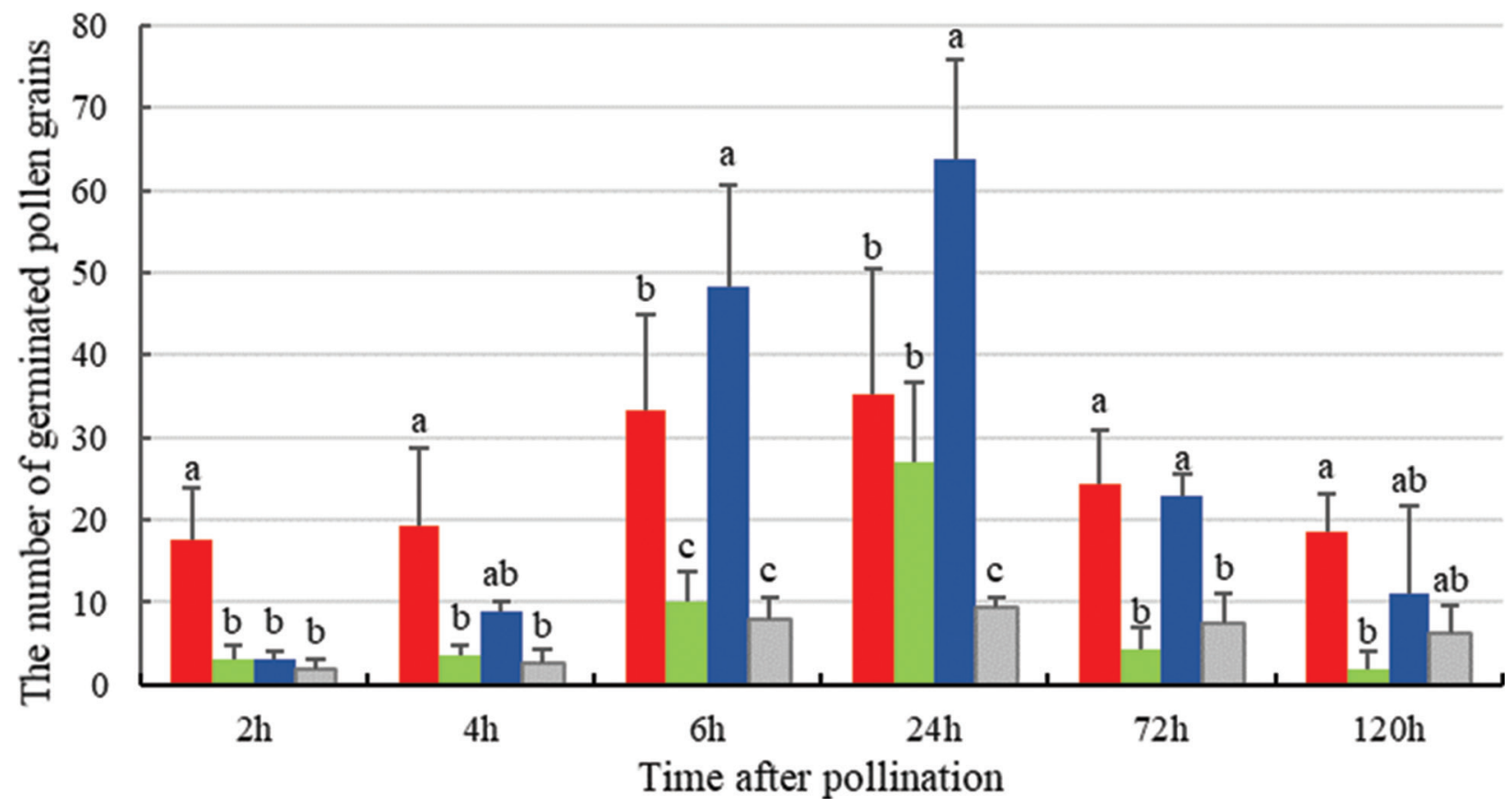

Figure 4. The number of germinated pollen grains on each cross combination after different pollination time. One-way ANOVA was used to assess statistical significance, and $p$ values were calculated with Tukey's HSD test $(\alpha=0.05)$. Multiple comparisons indicated by small letters were compared in different cross combinations within the same time after pollination. The data represent the mean value \pm standard deviation from three replicates. 
Table 3. Results of statistical analysis about pollination time and cross combination on the number of germinated pollen grains in Delphinium.

\begin{tabular}{|c|c|c|c|c|c|}
\hline Source of variation & Sum of square & Degree of freedom & Mean square & $F$ value & $p$-value \\
\hline Pollination time & 7034.9028 & 5 & 1406.9806 & 29.7860 & 0.0000 \\
\hline Cross combination & 6178.2639 & 3 & 2059.4213 & 43.5980 & 0.0000 \\
\hline Time $\times$ Combination & 4283.8194 & 15 & 285.5880 & 6.0460 & 0.0000 \\
\hline error & 2267.3333 & 48 & 47.2361 & & \\
\hline Total variations & $19,764.3194$ & 71 & & & \\
\hline
\end{tabular}

after pollination, showing pollen tubes entered the style and few callose deposited in the style (Figure 5A). After $4 \mathrm{~h}$, callose depositions appeared in large number in the style, some pollen tubes had entered the ovary at this stage. Six hours after pollination, pollen tubes arrived near the ovule and started to bend and twine. Finally, pollen tubes entered the ovule $24 \mathrm{~h}$ after pollination. In the reciprocal cross, pollen tube growth differs that in the orthogonal cross (Figure 5B). Only a small amount of pollen grains germinated on the stigma, whereas a large amount of callose deposition was visible in the style $2 \mathrm{~h}$ after pollination. Four hours after pollination, pollen tubes twined, knotted and spiraled, accompanied by callose formation. As a result, only a small number of pollen tubes reached the ovule $24 \mathrm{~h}$ after pollination, but none of them entered the ovule as observed.

In allogamic crosses of D. yunnanense, pollen tubes entered the ovule $24 \mathrm{~h}$ after pollination (Figure 5C). However, in the allogamic cross of D. elatum, a small amount of pollen germinated and callose deposition appeared $2 \mathrm{~h}$ after pollination. Six hours after pollination, the pollen tubes were visible in the style and reached the ovary $24 \mathrm{~h}$ after pollination (Figure 5D). Three days after pollination, the pollen tube entered the ovule. The pollen of D. yunnanense displayed a significantly strong interaction with stigmas of $D$. yunnanense and D. elatum, indicating that the pollen activity of $D$. yunnanense was stronger than that of D. elatum, which was in line with the results of pollen viability. It also suggested that $D$. elatum is more suitable as a maternal parent for hybridisation breeding.

\section{Fruit and seed setting of $F_{1}$ hybrids}

After crossing, the fruit set rate was evaluated in each cross according to the between the fruit number and the number of previously pollinated flowers. The results showed differences in fruit set rate between the orthogonal and reciprocal cross of D. yunnanense and D. elatum (Table 4). In the orthogonal cross (D. elatum $\times$ D. yunnanense), the fruit set rate was the highest $(90.0 \%)$ and generated 17.1 seeds per fruit. In contrast, there was no seed obtained in the reciprocal cross. This was consistent with the observation of microscopic dynamics that no pollen tube was found entering the ovule of $D$. yunnanense $\times D$. elatum. On the other hand, there was no significant difference in fruit set rate between the allogamic crosses of $D$. yunnanense and that of $D$. elatum, showing the rate of $86.7 \%$ and $83.3 \%$, respectively. Moreover, the seed number per fruit of $D$. elatum in allogamic cross was the highest, suggesting that there were no disturbances in the sexual reproductive system of $D$. elatum since both male and female lines were fertile. Therefore, the cross-incompatibility probably caused the sterility of D. yunnanense $\times D$. elatum $\mathrm{F}_{1}$ hybrids. Furthermore, the seed germination rate of $D$. elatum allogamic cross was the highest, while seeds derived from the cross of D. elatum $\times$ D. yunnanense displayed the lowest germination rate of $16.7 \%$ as well as the lowest thousand kernel weight. This may relate to the formation of abnormal seeds detected in the orthogonal cross of D. elatum $\times$ D. yunnanense.

\section{DISCUSSION}

The genus of Delphinium contains several species with a high ornamental value, which is crucial for the development of new floricultural varieties. In this study, we investigated the cross-compatibility of two Delphinium species, D. yunnanense, a wild endemic species of Yunnan province and a commercial variety D. elatum 'Guardian Blue'. Strong cross-incompatibility was observed in the cross of $D$. yunnanense $\times D$. elatum, whereas less cross-incompatibility was detected in the cross of $D$. elatum $\times D$. yunnanense, which provided a better understanding of the hybridisation affinity in Delphinium.

The measurement of pollen viability has an important theoretical and practical significance in hybrid breeding. The level of pollen viability affects the success and efficiency of hybrid breeding. Therefore, it is essential to measure the pollen viability before hybridisation, which could provide a useful reference for the formulation of hybrid combinations. Our results showed that the diurnal variation of pollen viability displayed a trend of increased in the morning but decreased in the afternoon in both D. yunnanense and D. elatum. This was consistent with previous independent observations of D. grandiflorum, in which the pollen viability increased at the early stage and decrease later in daily variation (from 9:30 to 15:30) with a peak at 11:30 AM (Zhang et al., 2014). Moreover, in Lilium davidii var. unicolor, 
A
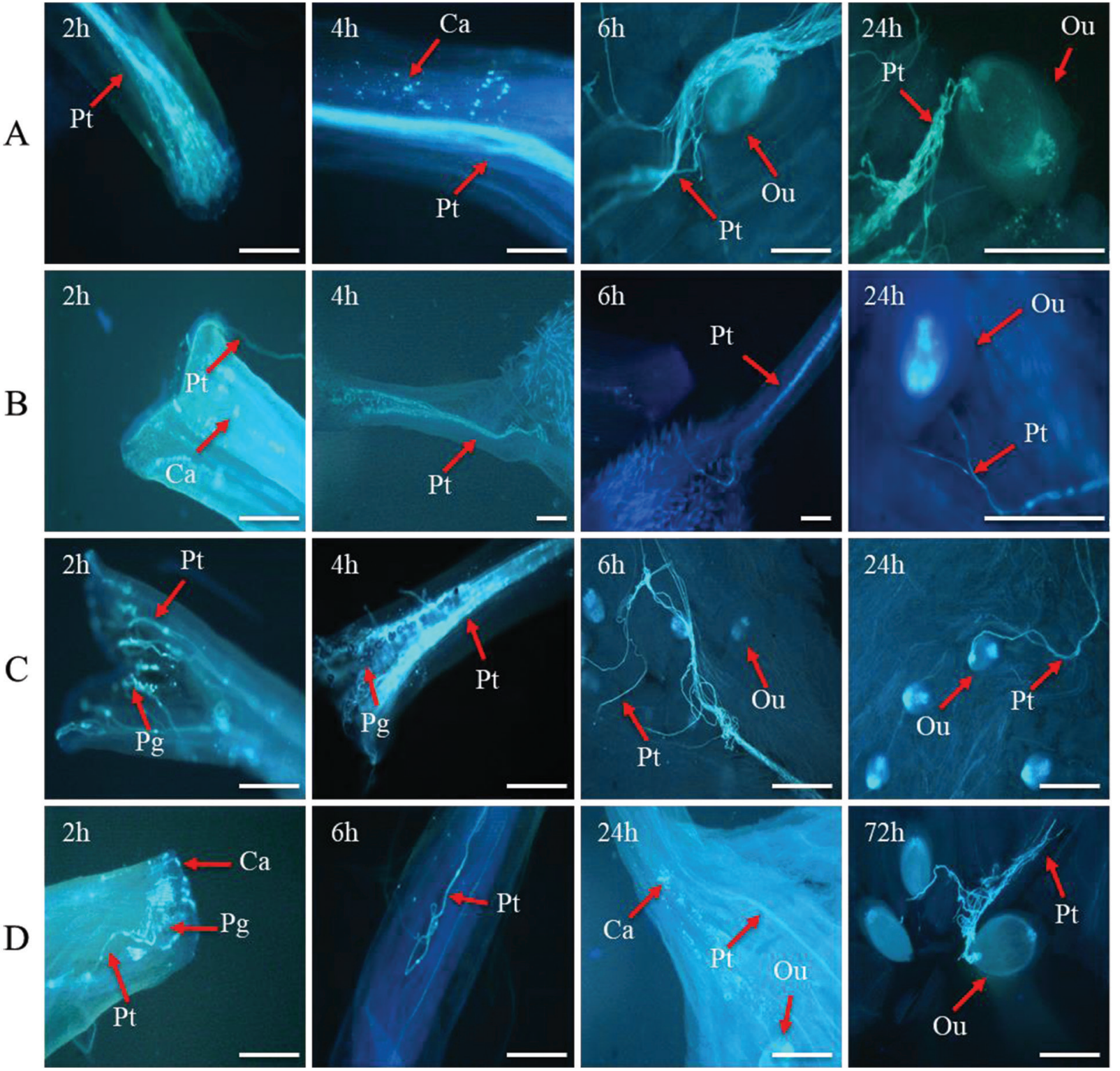

Figure 5. Dynamics of pollen tube growth of the interspecific and allogamic crosses between D. yunnanense and D. elatum. A: D. elatum $\times$ D. yunnanense. A-2h: A bundle of pollen tubes $(\mathrm{Pt})$ in the style of pistil, pollen grains $(\mathrm{Pg})$ visible on stigma. A-4h: Large number of callose (Ca) depositions appeared in the style. A-6h: Pollen tubes arrived near the ovule $(\mathrm{Ou})$ and started to bend and twine. A-24h: Pollen tubes entered the ovule. B: D. yunnanense $\times$ D. elatum. B-2h: Few pollen grains germinated on the stigma with a large amount of callose depositions visible in the style. B-4h: The twined, knotted and spiraled pollen tubes with callose. B-6h: Six hours after pollination, the state of pollen tube remains the same as $4 \mathrm{~h}$ after pollination. B-24h: Few pollen tubes were close to the ovule. C: D. yunnanense $\times$ D. yunnanens. C-2h: A number of pollen tubes in style of pistil, pollen grains also visible on stigma. C-4h: A bundle of pollen tubes grow along the style. C-6h: Pollen tubes arrived near the ovule. C-24h: Pollen tubes entered the ovule. D: D. elatum $\times$ D. elatum. D-2h: A small amount of pollen germinated and callose deposition appeared. D-6h: Pollen tubes were visible in the style. The pollen tubes were twined and knotted in the style. D-24h: Pollen tubes reached the ovary with visible callose deposition. D-72: Pollen tube entered the ovule. 'Pg' refers to pollen grain, 'Pt' means pollen tube, ' $\mathrm{Ca}$ ' is the abbreviation of callose and 'Ou' represents ovule. Bar $=200 \mu \mathrm{m}$.

the highest pollen vigor appeared at 08:00-14:00 with the highest germination rate appeared at 10:00 AM (Sun et al., 2019). The pollen vigor of D. yunnanense was significantly higher than that of $D$. elatum. This is probably because the pollen vigor of $D$. elatum has decreased after numerous artificial selections during the process of breeding.
Furthermore, we investigated the pollen-stigma interaction between $D$. yunnanense and D. elatum. The results showed that the number of pollen grains attached or germinated of D. yunnanense were relatively higher in the reciprocal or allogamic crosses. This was in line with the large pollen quantity and high pollen vitality of D. yunnanense. Moreover, it was detected that no pollen 
Table 4. Characteristics of $\mathrm{F}_{1}$ seeds in the interspecific and allogamic cross of D. yunnanense and D. elatum.

\begin{tabular}{|c|c|c|c|c|c|c|c|}
\hline Cross combination & $\begin{array}{l}\text { Pollinated } \\
\text { flowers } \\
\text { number }\end{array}$ & $\begin{array}{c}\text { Fruit } \\
\text { number }\end{array}$ & $\begin{array}{l}\text { Fruit set } \\
\text { rate }\end{array}$ & $\begin{array}{c}\text { Seed } \\
\text { number }\end{array}$ & $\begin{array}{c}\text { Seed } \\
\text { number per } \\
\text { fruit }\end{array}$ & $\begin{array}{l}\text { Thousand } \\
\text { kernel weight } \\
\text { (g) }\end{array}$ & $\begin{array}{c}\mathrm{F}_{1} \text { seed } \\
\text { germination rate } \\
(\%)\end{array}$ \\
\hline $\begin{array}{l}\text { D. elatum } \times \\
\text { D. yunnanense }\end{array}$ & 30 & 27 & $90.0 \%$ & 463 & 17.1 & 1.3 & $16.7 \pm 2.08 \mathrm{a}$ \\
\hline $\begin{array}{l}\text { D. yunnanense } \times \\
\text { D. elatum }\end{array}$ & 30 & 0 & $0.0 \%$ & l & / & l & l \\
\hline $\begin{array}{l}\text { D. yunnanense } \times \\
\text { D. yunnanense }\end{array}$ & 30 & 26 & $86.7 \%$ & 421 & 16.2 & 1.7 & $24.7 \pm 2.52 \mathrm{~b}$ \\
\hline $\begin{array}{l}\text { D. elatum } \times \\
\text { D. elatum }\end{array}$ & 30 & 25 & $83.3 \%$ & 527 & 21.1 & 2.0 & $80.0 \pm 4.00 \mathrm{c}$ \\
\hline
\end{tabular}

One-way ANOVA was used to assess statistical significance, and $p$ values were calculated with Tukey's HSD test $(\alpha=0.05)$.

tube entered the ovule in the reciprocal cross, suggesting that there was a strong cross-incompatibility in the reciprocal cross of $D$. yunnanense $\times D$. elatum. This was related to the cell recognition of the pollen-stigma interaction, which could prevent pollen with genetic variation from germinating on stigma and entering into ovule (Bedinger et al., 2017). It was reported that pre-fertilisation obstacles of interspecific hybridisation in plants were mainly caused by the abnormal growth of pollen tubes, the callose formed on stigma surface and excessive growth of pollen tubes (Heslop-Harrison, 1982; Dumas and Knox, 1983). In our study, the abnormal growth of pollen tubes was observed in the cross of $D$. yunnanense $\times D$. elatum, such as winded, knotted and spiraled pollen tubes. The formation of callose in stigma mastoid cells was also observed after pollination, which prevented the pollen tube from entering the ovule and consequently resulted in the lack of fertilisation and seed production. Moreover, barriers to reproduction are the most important factor for cross-incompatibility, which can be effective before (prezygotic barriers) and after (postzygotic barriers) the formation of a zygote (Pease et al., 2016). Prezygotic barriers are arguably the most important and effective barriers that contribute to reproductive isolation acting before hybrids formation (Henrich and Kalbe, 2016). In the cross of D. yunnanense $\times D$. elatum, although some pollen grains germinated, the pollen tubes were arrested in the pistils and were unable to reach the ovules. Thus, the pre-fertilisation reproductive barriers are the main factor affecting the cross of $D$. yunnanense $\times$ D. elatum. This phenomenon was also observed in the crosses of different petal phenotypes in Jasminum sambac Aiton (Deng et al., 2017).

Although the fruit set ratio of D. elatum $\times$ D. yunnanense was the highest and plenty of $\mathrm{F}_{1}$ seeds were generated, yet the germination ratio of $\mathrm{F}_{1}$ seeds was really low. In addition, we did not harvest any seed or fruit from the cross of $D$. yunnanense $\times D$. elatum. These results demonstrated that the incompatibility indeed existed between D. yunnanense and D. elatum. One possible theory is that the development of embryo was disturbed and generated immature seed with normal appearance but containing aborted embryos, which reduced the seed vitality (Zeng et al., 2010; Chai et al., 2011; Dai et al., 2014; Chong et al., 2018). This also indicated by the thousand kernel weight of $\mathrm{F}_{1}$ seeds in D. elatum $\times$ D. yunnanense, which displayed the lowest thousand kernel weight. Moreover, the germination traits study of $D$. chefoense showed that the seed germination rate was about $38.0 \%$ and $7.3 \%$ under $20^{\circ} \mathrm{C}$ and $25^{\circ} \mathrm{C}$, respectively (Qian, 2012). In our study, the seed germination rate of $D$. yunnanense was about $24.7 \%$ at $25^{\circ} \mathrm{C}$. The similar low seed germination rate of the wild type in Delphinium species indicated that reproductive strategy of this genus was relatively conserved, which probably provides high recruitment rates for the existing populations with numerous, but the genetic variation and regeneration of natural population may not be able to maintain in the long term (Orellana et al., 2009). Thus, it is necessary to protect the species in Delphinium, since it was also reported that the species number of Delphinium decreased in China (Yuan, 2006). In conclusion, our study provided a fundamental information for the cross-incompatibility in D. yunnanense and D. elatum related to hybridisation. These findings may help ornamental breeders overcome reproductive barriers to develop new cultivars in the species.

\section{FUNDING}

This work was funded by the Major Science and Technology Project of Yunnan Provincial Science and Technology Department (2019ZG006), the Special Funding for High-end Talents Cultivation of Floriculture Research Institute from Yunnan Provincial Department of Finance (530000210000000024520), the Innovative Talents Training Base for High-level Universities in Yunnan Province-Horticulture Innovation and Entrepreneurship Training Program (2016CX001), and the Construction of Modern Agricultural Industry System in Floriculture and Seedling in Yunnan Province (2017KJTX0010). We thank Dr. Chunlian Jin (Ghent University) for assistance with the English language grammar and syntax of this manuscript. 


\section{AUTHOR CONTRIBUTIONS}

Y.C. and W.G. conceived and designed the experiments. Y.C. completed the experiments. Y.C. and F.L. conducted the data analysis and drafted the manuscript. F.L. critically revised the manuscript. W.G. and F.L. jointly provided supervision. All authors reviewed and approved the manuscript.

\section{CONFLICT OF INTEREST}

The authors declare no conflict of interest.

\section{REFERENCES}

Agnihotri, P., Jena, S., Husain, D., And Husain, T. (2014). Perspective of the genus Delphinium Linnaeus (Ranunculaceae) in India. Pleione, 8, 344-352.

Bedinger, P. A., Broz, A. K., Tovar-Mendez, A., And Mcclure, B. (2017). Pollen-pistil interactions and their role in mate selection. Plant Physiology, 173, 79 .

Bosch, M., Simon, J., Molero, J., and Blanché, C. (2001). Breeding systems in tribe Delphinieae (Ranunculaceae) in the western Mediterranean area. Flora, 196, 101-113.

Briggs, H. M., Anderson, L. M., Atalla, L. M., Delva, A. M., Dobbs, E. K., And Brosi, B. J. (2016). Heterospecific pollen deposition in Delphinium barbeyi: linking stigmatic pollen loads to reproductive output in the field. Annals of Botany 117, 341-347.

Chai, L., Ge, X., Biswas, M. K., Xu, Q., and Deng, X. (2011). Self-sterility in the mutant 'Zigui shatian' pummelo (Citrus grandis Osbeck) is due to abnormal post-zygotic embryo development and not self-incompatibility. Plant Cell, Tissue and Organ Culture, 104, 1-11.

Chen, F. Z., Chen, Q. H., And Wang, F. P. (2011). Diterpenoid alkaloids from Delphinium yunnanense. Helvetica Chimica Acta, 94, 254-260.

Chong, W., Weili, H. E., Wei, Z., And Jiajun, L. (2018). Fluorescence observation of pollen tube growth and embryo culture from distant hybridization between asiatic and oriental lily cultivars. Northern Horticulture, 10, 88-96.

Dai, S. J., Qi, J. X., DuAn, C. R., Wang, Y. P., Chen, P., Li, Q., HaO, Y. B., And Leng, P. (2014). Abnormal development of pollen and embryo sacs contributes to poor fruit set in walnut (Juglans hopeiensis). Journal of Horticultural Science and Biotechnology, 89, 273-278.

Deng, Y., Sun, X., Gu, C., Jia, X., Liang, L., and Su, J. (2017). Identification of pre-fertilization reproductive barriers and the underlying cytological mechanism in crosses among three petal-types of Jasminum sambac and their relevance to phylogenetic relationships. PLoS ONE, 12, e0176026, doi: 10.1371/ journal.pone.0176026.
Dumas, C., And Knox, R. B. (1983). Callose and determination of pistil viability and incompatibility. Theoretical and Applied Genetics, 67, 1-10.

Elliott, S. E., ANd Irwin, R. E. (2009). Effects of flowering plant density on pollinator visitation, pollen receipt, and seed production in Delphinium barbeyi (Ranunculaceae). American Journal of Botany, 96, 912-919.

Guan, W., AND Li, S. (2002). Ornamental germplasm resources of genus Delphinium in Yunnan. Subtropical Plant Science, 31, 61-64.

He, G., Hu, F., Ming, J., Liu, C., and Yuan, S. (2017). Pollen viability and stigma receptivity in Lilium during anthesis. Euphytica, 213, 231, doi: 10.1007/ s10681-017-2019-9.

Henrich, T., And Kalbe, M. (2016). The role of prezygotic isolation mechanisms in the divergence of two parasite species. BMC Evolutionary Biology, 16, 245, doi: 10.1186/s12862-016-0799-5.

Heslop-Harrison, J. (1982). Pollen-stigma interaction and cross-incompatibility in the grasses. Science, 215(4538), 1358-1364.

Honda, K., Tsutsui, K., and Hosokawa, K. (1999). Analysis of the flower pigments of some Delphinium species and their interspecific hybrids produced via ovule culture. Scientia Horticulturae, 82, 125-134.

Legro, R. A. H. (1961). Species hybrids in Delphinium. Euphytica, 10, 1-23.

Lewis, H., Epling, C., Mehlquist, G. A. L., And Wyckoff, C. G. (1951). Chromosome numbers of Californian Delphiniums and their geographical occurrence. Annals of the Missouri Botanical Garden, 38, 101-117.

Li, T., Liu, X., Li, Z., Ma, H., Wan, Y., Liu, X., AND Fu, L. (2018). Study on reproductive biology of Rhododendron longipedicellatum: A newly discovered and special threatened plant surviving in limestone habitat in Southeast Yunnan, China. Frontiers in Plant Science, 9, 33, doi: 10.3389/ fpls.2018.00033.

Lin, C.-Z., ZhaO, Z.-X., Xie, S.-M., MaO, J.-H., Zhu, C.-C., Li, X.-H., Bairi, Z.-D., Kangsa, S.-Q., Dun, Z., AND XIONG, T.-Q. (2014). Diterpenoid alkaloids and flavonoids from Delphinium trichophorum. Phytochemistry, 97, 88-95.

MAcior, L. W. (1975). The pollination ecology of Delphinium tricorne (Ranunculaceae). American Journal of Botany, 62, 1009-1016.

Malyutin, N. (2001). The system of the genus Delphinium (Ranunculaceae). Botanicheskiy zhurnal [Botanical Journal], 86, 120-130.

Mehlquist, G. A. L., Blodget, C. O., and Bruscia, L. (1943). Colchicine induced tetraploidy in Delphinium cardinale. Journal Heredity, 34(6), 187-192.

Orellana, M. R., López-Pujol, J., Blanché, C., Rovira, A. M., AND Bosch, M. (2009). Genetic diversity in Delphinium staphisagria (Ranunculaceae), a rare 
Mediterranean dysploid larkspur with medicinal uses. Genetica, 135, 221-232.

Pease, J. B., Guerrero, R. F., Sherman, N. A., Hahn, M. W., And Moyle, L. C. (2016). Molecular mechanisms of postmating prezygotic reproductive isolation uncovered by transcriptome analysis. Molecular Ecology, 25, 2592-2608.

Powell, E., ANd Jones, C. (1983). Floral mutualism in Lupinus benthamii (Fabaceae) and Delphinium parryi (Ranunculaceae). In C. E. Jones and R. J. Little (Eds), Handbook of Experimental Pollination Biology (pp. 310-329). New York: Van Nostrand Reinhold.

Price, M., And Waser, N. (1979). Pollen dispersal and optimal outcrossing in Delphinium nelsoni. Nature, 277, 294-297.

QIAN, W. (2012). Study of morphological characteristics and germination traits of Delphinium chefoense franch seeds. Journal of Anhui Agricultural Sciences, 40, 9236-9238.

Rodriguez-Riano, T., and Dafni, A. (2000). A new procedure to asses pollen viability. Sexual Plant Reproduction, 12, 241-244.

Royal Horticultural Society. (1949). A tentative check-list of Delphinium names (1-112). London, UK: Royal Horticultural Society.

Samuelson, A. A. (1957). Wild Delphiniums and their hybrids. London, UK: Delph. Soc. Year Book.

Sun, H. Q., Shi, G. Y., Ran, B., Zhang, L., AND JIA, X. X. (2019). Pollen viability, stigma receptivity and breeding system of Lanzhou Lily. Journal of Desert Research, 39, 62-69.

Tang, Q. Y., and Zhang, C. X. (2013). Data Processing System (DPS) software with experimental design, statistical analysis and data mining developed for use in entomological research. Insect Science, 20, 254-260.

Tuebbes, K. (2010). The chromosomes of three Delphinium species. Hereditas, 10, 160-164.

VARnEY, D. M. (1979). Reproductive biology of four species of Delphinium endemic, to the Wenatchee Mountains. USA: University of Washington.
WANG, W., AND WARnock, M. J. (2001). Delphinium Linnaeus. In Z. Wu and P. H. Raven (Eds.). Flora of China 6 (pp. 223-237). Beijing/St. Louis: Science Press/Missouri Botanical Garden.

Wegulo, S. N. And Vilchez, M. (2008). Evaluation of Delphinium cultivars for resistance to powdery mildew. HortTechnology, 18, 407-409.

Williams, C. F. (2007). Effects of floral display size and biparental inbreeding on outcrossing rates in Delphinium barbeyi (Ranunculaceae). American Journal of Botany, 94, 1696-1705.

Williams, C. F., Ruvinsky, J., Scott, P. E., and Hews, D. K. (2001). Pollination, breeding system, and genetic structure in two sympatric Delphinium (Ranunculaceae) species. American Journal of Botany, 88, 1623-1633.

YuAN, Q. (2006). The genus Delphinium L. from the Hengduan Mountains region in Southwestern China: Taxonomy and cytology. PhD Dissertation, Chinese Academy of Sciences, Beijing, China.

Yuan, Q., AND YanG, Q.-E. (2008). Low incidence of polyploids and high uniformity of karyotypes displayed by Delphinium (Ranunculaceae) in the Hengduan Mountains region of Southwest China. Botanical Journal of the Linnean Society, 158, 172-188.

YuAn, Q., AND YANG, Q.-E. (2019). Taxonomic studies on the genus Delphinium (Ranunculaceae) from China (XXI): The identities of D. breviscaposum and D. filibracteolum from northwestern Yunnan. Phytotaxa, 420, 185-197.

ZenG, Y. X., Hu, C. Y., Lu, Y. G., Li, J. Q., And Liu, X. D. (2010). Diversity of abnormal embryo sacs in indica/ japonica hybrids in rice demonstrated by confocal microscopy of ovaries. Plant Breeding, 126, 574-580.

Zhang, H., Zhao, J., Xin, H., and Zhang, J. (2014). Study on pollination biology of wild Delphinium grandiflorum. Acta Botanica Boreali-Occidentalia Sinica, 34, 1789-1794.

Received: July 15, 2020; accepted: October 21, 2020. 